\title{
Crill: A novel technique to characterize nano-ligno-cellulose
}

\author{
Sinke H. Osong, Sven Norgren, Per Engstrand, Mathias Lundberg and Peter Hansen
}

\begin{abstract}
KEYWORDS: Mechanical pulp fines, Fractionation, Homogenization, Nano-ligno-cellulose, Crill

SUMMARY: The CrillEye is a technique for qualitatively assessing loose slender and fibrillar particles created during pulping. It has also been demonstrated that the crill measurement technique can easily be used to measure the degree of fibrillation of mechanical pulp based nano-ligno-cellulose (NLC). The measurement technique is based on an optical response of a suspension at two wavelengths of light; UV and IR. The UV light contains information on both fibres and crill, while IR only contains information on fibres. The resolution on the CrillEye module is based on optical response of the pulp and on an analogue signal analysis making it concentration independent. Characterization of particlesize distribution of nano-ligno-cellulose is both important and challenging. The objective of the work presented in this paper was to study the crill values of TMP and CTMP based nano-ligno-celluloses as a function of homogenization time. Results showed that the crill value of both TMP-NLC and CTMP-NLC correlated fairly well with the homogenization time.
\end{abstract}

\section{ADDRESSES OF THE AUTHORS:}

Sinke H. Osong (henshaw.sinke@miun.se),

Sven Norgren (sven.norgren@miun.se),

Per Engstrand (per.engstrand@ miun.se),

FSCN, Mid Sweden University, 851 70, Sundsvall.

Mathias Lundberg (mathias.lundberg@pulpeye.com):

PulpEye AB, Address: Box 279, SE-891 26

ÖRNSKÖLDSVIK, Sweden, Peter Hansen (peter.hansen@innventia.com): INNVENTIA AB, Drottning Kristinas väg 61, Stockholm, Sweden.

\section{Corresponding author: Sinke H. Osong}

Wood is a biodegradable biopolymer and constitutes of three principal chemical components; cellulose, lignin and hemicelluloses. Mechanical pulping is a process in which wood logs are mechanically treated in a grinder or refiner in order to obtain fibre particles. The mechanical pulp consist of ; stone groundwood (SGW), pressure groundwood (PGW), super pressure groundwood (PGW$\mathrm{S})$, thermo-groundwood (TGW), refiner mechanical pulp (RMP), pressure refiner mechanical pulp (PRMP), thermo-mechanical pulp (TMP), chemi-mechanical (CMP) and chemi-thermomechanical (CTMP) (Sundholm 1999). Thermomechanical pulp (TMP) and chemithermomechanical pulping (CTMP) are the two main pulps of interest in this study. Pulps are made up of fibres and fines. The fines are regarded as particles that pass through a 200 mesh wire of a Bauer-McNett $(\mathrm{BMcN})$ Classifier or Britt Dynamic Drainage Jar (BDDJ) (Seth 2003, Sundberg, Holmbom 2004). Fine particles have been categorized as flakes or lamellae, thread-like bands or fibrils, tori from bordered pits, parenchyma cells and ray tracheids (Westermark, Capretti 1988; Seth 2003; Sundberg, Holmbom 2004).
Research work in the field of microfibrillated cellulose or nanocellulose began in the late 1970s by researchers working at ITT Rayonier Eastern Research Division Laboratory in Whippany, New Jersey, USA (Charreau et al. 2013). They used a mechanical high-pressure homogenizer known as Manton Gaulin-type milk homogenizer to produce thread-like particles referred to as microfibrillated cellulose or nanocellulose. Pulp is disintegrated into loose slender and fibrillar particles known as microfibrillated cellulose (Turbak et al. 1983; Herrick et al. 1983). The type of material produced by high shear forces in a high pressure homogenizer or microfluidizer has been called a variety of names such as microfibrillated cellulose or nanocellulose, microfibrillar cellulose, microfibrillized cellulose, nanofibrillated cellulose, nanofibrillar cellulose, nanoscale fibrillar cellulose and cellulosic fibrillar fines (Moon et al. 2011; Hubbe et al. 2008; Siro, Plackett 2010; Siqueira et al. 2010; Eichhorn et al. 2010; Klemm et al. 2011; Charreau et al. 2013). According to Tappi standard (2011) however, it should be called cellulose nanofibrils (CNF) or cellulose microfibrils (CMF).

The production route of microfibrillated cellulose is based on passage of pulp slurries into a high pressure homogenizer. The pulps are usually chemically (Saito et al. 2007) or enzymatically (Henriksson et al. 2007; Pääkkö et al. 2007) pre-treated in a way to; lower energy consumption, improve fibrillation and also to avoid fibre clogging. It is well known that, the rate of fibrillation is dependent on the pressure drop and the number of homogenisation passes. Mechanical pulps are not easy to treat in the homogenizer to form well fibrillated fibrils. This is because of the cellulose/hemicellulose/lignin interaction, the lignin in the pulp acts as a gluing substance to cellulose thus preventing the cellulose molecules from complete individualization, thereby forming fibril bundles.

Nowadays, in pulp mills, optical analyzers are often used for fibre characterisation in order to determine particle size (fibre length, width and fibre wall thickness) distribution of pulps in the micron-scale. However, with these methods, it is not possible to effectively measure fibre size distribution in the submicron or nano -scale. The CrillEye module of the PulpEye $\AA$ analyzer could be an instrument to tackle this limitation of optical analyzers in relation to particle size. The resolution on the CrillEye module is based on optical response of the pulp and on an analogue signal analysis making it concentration independent. The Crill module is dependent on the wavelength of light (non-polarized light), surface chemistry of the particles in the pulp and the signal filtering and analysis.

Most of the optical analyzers such as Kajaani FiberLab, MorFi and Fibermaster can be used to measure fibre length, width, and fibre wall thickness of various types of 
pulp samples. These instruments categorize fines as particles that are less than $0.20 \mathrm{~mm}$ in length (Guay et al. 2005). But it has been noticed that these optical analyzing equipments cannot effectively measure very thin and slender particles, i.e. particles less than $0.20 \mathrm{~mm}$ in length. The main reason could be due to their poor resolution. Guay et al. (2005) have reported the resolutions of these optical analyzers as such; Kajaani FiberLab (10 $\mu \mathrm{m}$, using a polarized light source), MorFi (4 $\mu \mathrm{m}$, using a non-polarized light source) and Fibermaster (26 $\mu \mathrm{m}$, using a non-polarized light source) operating with a normal camera. However, with the CrillEye module, it is possible to measure very thin and slender pulp particles down to $0.20 \mu \mathrm{m}$ in thickness.

During the last three decades several methods have been used to characterize microfibrillated cellulose including the microscopical techniques which qualitatively assess the degree of fibrillation of cellulose nanofibrils. The main draw-back of the microscopical technique (image analysis) is that it is not always suitable in relation to quality control in the industry. An alternative method to the microscopical technique could be the crill measurement method. This technique does not require image analysis thereby making it a very fast method and this enables it for quality adjustment in online process. It has also been shown that the technique is used in qualitatively assessing hairy fibres during pulp processing and could thus, be used in the mill for quality control during refining (Pettersson 2010). The crill was first described by Steenberg et al. (1960) as loose slender and fibrillar particles. Steenberg et al. (1960) mentioned that the name "crill" is derived from the Norwegian term denoting a pelagic organism. Historically, the crill measurement method, developed by PulpEye AB, uses the method from the Innventia (former STFI) OptoCrill developed in the early 1980s by Thorulf Pettersson and co-workers. The development resulted in signal analysis methodology that was awarded the Wallenberg Prize in 1995 and was the foundation for a series of measurement systems developed in the 1980s. The fast development of computers, image analysis and CCD-cameras, however, favored the development of image based measurements techniques. The crill measurement was brought to attention again by Ulla-Britt Mohlin in the research program on LC-refining at Innventia during 2003-2011. The methodology was transferred to PulpEye $\mathrm{AB}$ during 2012 by financial support from VINNOVA. Characterization of particle-size distribution of nano-ligno-cellulose is both important and challenging.

The objective of the work presented in this paper was to study the crill values of TMP and CTMP based nanoligno-celluloses as a function of homogenization time. In this investigation, the term nano-ligno-cellulose (NLC) is used and not the commonly used names such microfibrillated cellulose or nanocellulose.

\section{Materials and Methods}

\section{Thermo-mechanical pulp (TMP)}

The TMP sample used in this work was collected from SCA pulp mill at Örtviken, Sundsvall, Sweden. It has a
Canadian Standard Freeness (CSF) value of $60 \mathrm{ml}$, wood type is $100 \%$ fresh Norway spruce (Picea abies) produced for newsprint grade. The pulp was stored in a refrigerator before use. The nanocellulose produced from TMP is referred to as TMP-NLC in this work.

\section{Chemi-thermomechanical pulp (CTMP)}

The CTMP sample used in this investigation was obtained from SCA Östrand pulp mill, Sundsvall, Sweden. The wood material used was solely never-dried fresh Norway spruce (Picea abies), with a high Canadian Standard Freeness (CSF) of about $619 \mathrm{ml}$ and an ISO brightness of $76 \%$. The pulp was stored in a refrigerator before use. The nanocellulose produced from CTMP is referred to as CTMP-NLC in this work.

\section{Britt Dynamic Drainage Jar (BDDJ) fractionation}

In this paper, the pulps were fractionated using a specially designed BDDJ at the SCA Research Centre in Sundsvall, with a capacity of 8 litres. Pulps were disintegrated at 30000 number of revolutions and diluted using 8 litres of tap water. $30 \mathrm{~g}$ of pulp (o.d.) was used for each fractionation. The fine fractions were obtained from the pulp samples by BDDJ fractionation technique. The fractions passing through the 30 mesh wire screen are regarded as "fines" while the retained fractions on the 30 mesh wire screen were discarded. The cut-off or pore size of the BDDJ 30mesh screen was approximately $600 \mu \mathrm{m}$. The reason for fibre fractionation is to obtain short and tiny fibres that could be easily homogenized.

\section{Homogenization}

A GEA Niro Soavi homogenizer (ARIETE, Model: NS2006H, Serial Number: 8755, 2010, Parma-Italy) was used to produce nano-ligno-cellulose.The working principle of the high pressure homogenizer is that it subjects the pulp slurries to high impact force and high shear rate due to the reciprocating action within the valves. The pulp suspension undergoes the process of high pressure micronization to reduce the size of the fibres so as to obtain a stable suspension. The homogenisation experiments in this study were performed using thermo-mechanical pulp and chemi-thermo mechanical pulp fines. A schematic diagram of a high pressure homogenizing equipment is shown in Fig la. The pulp slurries were treated in the homogenizing equipment at approximately $1 \%$ consistency for $120 \mathrm{~min}$; and at a homogenization pressure in the range of 200-300 bars (Table 1).

Table 1 - Pulp sample homogenisation conditions

\begin{tabular}{cccc}
\hline $\begin{array}{c}\text { Pulp } \\
\text { Number }\end{array}$ & $\begin{array}{c}\text { Pulp } \\
\text { Descrip } \\
\text {-tion }\end{array}$ & $\begin{array}{c}\text { Homogenisation } \\
\text { temperature }\left({ }^{\circ} \mathrm{C}\right)\end{array}$ & $\begin{array}{c}\text { Homogenisation } \\
\text { pressure (bars) }\end{array}$ \\
\hline $\mathbf{1}$ & TMP & 23 & $200-300$ \\
$\mathbf{2}$ & TMP & 140 & $200-300$ \\
$\mathbf{3}$ & CTMP & 23 & $200-300$ \\
$\mathbf{4}$ & CTMP & 140 & $200-300$ \\
\hline
\end{tabular}




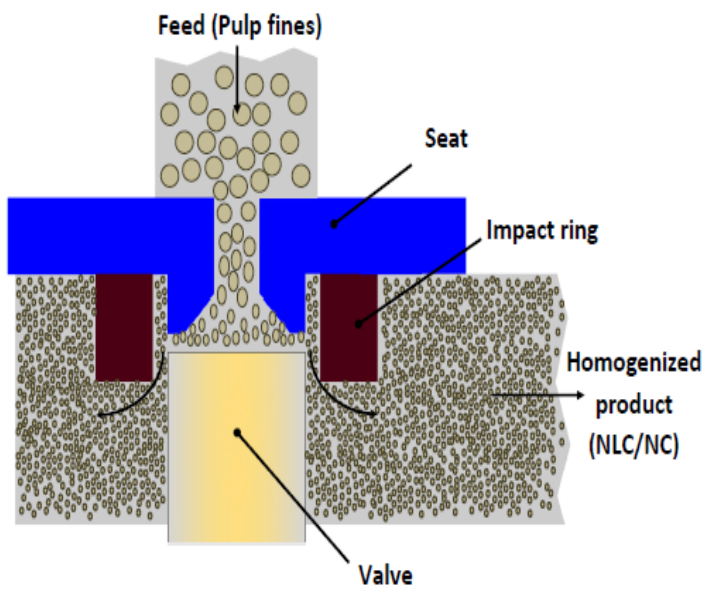

Fig1a - Schematic diagram of a high pressure homogenizer

\section{PulpEye $®$ - CrillEye}

The crill has been used for chemical pulp evaluation, and it is for this reason that we have placed more attention on crill measurement related to nano-ligno-cellulose. As for any online measurement, the technique used should be robust, precise, fast and stable during production. The crill measurements were done at Dynäs Mondi Mill in Kramfors, Sweden, and the measurement we done manually (offline). To the best of our knowledge, no articles are available concerning the measurement of crill using mechanical pulp based nano-ligno-cellulose. In this study a PulpEye ${ }^{\circledR}$ Online Analyzer (PulpEye AB, 2005, Örnsköldsvik-Sweden) was used in characterising the crill value of the microfibrils or the nano-ligno-cellulose suspension. $1 \mathrm{~g}$ dry solid content of NLC was used in all investigations. For the fibre quality measurement using the PulpEye Analyzer, $20 \mathrm{~g}$ oven dried pulp was used in all investigations. The measurement of crill is based on optical response of a suspension at two wavelengths of light; UV and IR. The UV light contains information on both the total fibres and the crill, while IR only contains information on fibres (Fig 1 b). KFP = "crill value", and is a concentration independent ratio which takes into account the UV value (fibre + crill area) divided by the IR value (fibre area) (Hansen, Sundvall 2012). Table 1 list the various pulp types analyzed during this project.

\section{Results and Discussion}

This work describes a new approach of assessing fibrillation efficiency of macroscopic pulp fibres to sub microfibrils as a function of the number of homogenization passes (time). The working principle of the high pressure homogenizer is that it subjects the pulp fibres to high impact force and high shear rate due to the reciprocating action within the valves, see Fig la. The fibre suspension undergoes the process of high pressure treatment to reduce the size of the fiber particle in the sub-micron scale. The valve seats in the homogenizer experience an increase in temperature with time during operation; the homogenizer in this project works conveniently at room temperature $\left(23^{\circ} \mathrm{C}\right)$ as well at high temperature $\left(140^{\circ} \mathrm{C}\right)$. It is seen in Fig $2-5$ that as the number of homogenization passes increases, the fibrillation efficiency is improved.

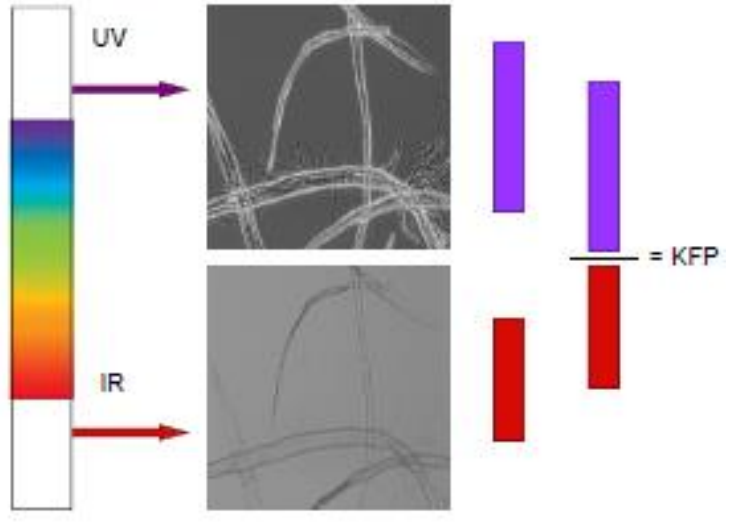

Fig $1 \mathrm{~b}$ - An illustration of the measurement principle of crill value, KFP = "crill value" (by courtesy of Innventia). The images are obtained by phase contrast microscopy to illustrate outer fibrillation of fibres. The crill measurement method is however not based on imaging techniques.

Results from the PulpEye ${ }^{\circledR}$ analyzer are given in Table 2. The results show that the fibre TMP had a fibre length of $1.25 \mathrm{~mm}$ and $42.3 \%$ amount of fines meanwhile, CTMP had an average fibre length of $1.74 \mathrm{~mm}$ and $30.7 \%$ fine content (Table 2).

Experimental results from crill measurements are presented and discussed in Fig 2-5 based on data obtained from the CrillEye module of the PulpEye ${ }^{\circledR}$ Online Analyzer. The aim of the study was to measure the crill value of thermo-mechanical pulp (TMP) and chemithermomechanical pulp (CTMP) based nano-lignocellulose and relate this with the number of homogenization passes (time). The two main challenges involve during homogenization are the huge amount of energy consumption and fibre clogging (Herrick et al. 1983; Turbak et al. 1983; Ankerfors 2012). Most of the energy losses in the homogenizer are due to friction that occurs at the seats, valves and impact ring. As the number of homogenization passes of the pulp suspension increases, the amount of energy consumption also increases. The clogging blocks the flow of pulp suspension and renders the process to become unstable, and hence the whole assembly needs dismantling and reassembly. It has been demonstrated that the crill measurement technique can easily be used to measure the degree of fibrillation of NLC. The results showed that the crill value of both TMP-NLC and CTMP-NLC correlated fairly well with the homogenization time. The increasing trend of the crill value is more pronounce within the first $20 \mathrm{~min}$ of homogenization for all the samples.

Table 2 - Fibre characterisation using PulpEye® Analyzer.

\begin{tabular}{llllll}
\hline $\begin{array}{l}\text { Pulp } \\
\text { samples }\end{array}$ & $\begin{array}{l}\text { Freeness/ } \\
\text { SR }(\mathbf{m l})\end{array}$ & $\begin{array}{l}\text { Fibre } \\
\text { length } \\
(\mathbf{m m})\end{array}$ & $\begin{array}{l}\text { Fibre } \\
\text { width } \\
(\boldsymbol{\mu m})\end{array}$ & $\begin{array}{l}\text { Curl } \\
(\%)\end{array}$ & $\begin{array}{l}\text { Fines } \\
(\%)\end{array}$ \\
\hline TMP & 43.1 & 1.25 & 33.6 & 13.4 & 42.3 \\
CTMP & 17.4 & 1.74 & 38.1 & 10.9 & 30.7 \\
\hline
\end{tabular}

SR = Schopper-Riegler. 


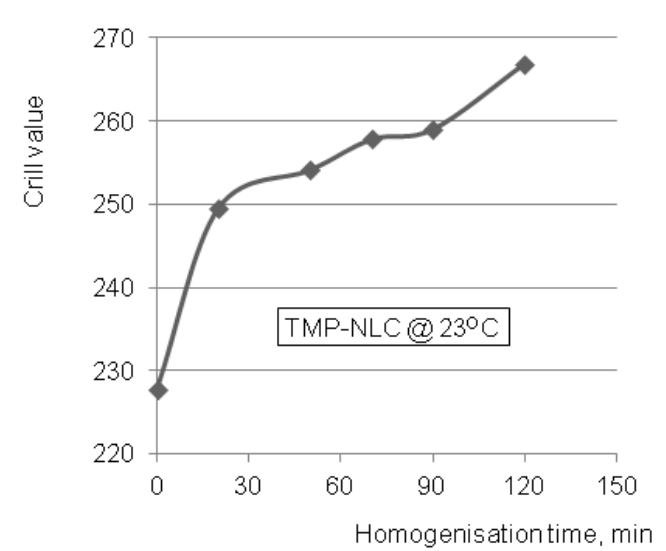

Fig 2 - Crill value of TMP-NLC homogenised at a starting temperature of $23^{\circ} \mathrm{C}$ as a function of homogenisation time.

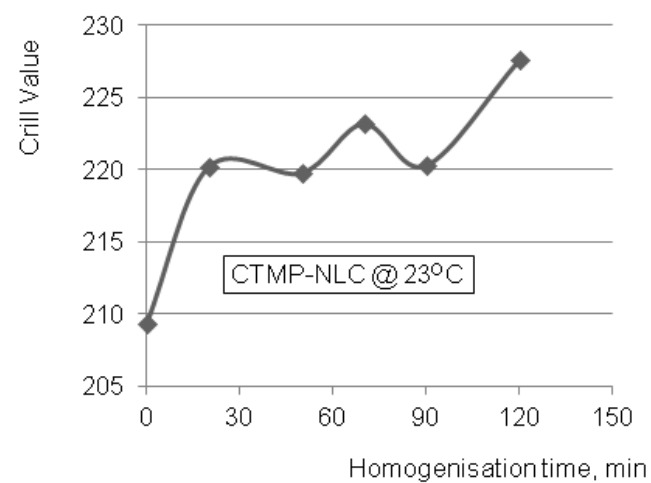

Fig 4 - Crill value of CTMP-NLC homogenised at a starting temperature of $23^{\circ} \mathrm{C}$ as a function of homogenisation time.

A commercial online crill sensor was used to qualitatively evaluate the fibre-size distribution of the nano-ligno-cellulose suspension. Results showed that the crill value correlated fairly well with the homogenization time (Fig 2-5). The measuring principle of the crill value is schematically illustrated in Fig $1 b$. The crill sensor makes measurements of crill both rapidly and frequently, which means that it is very suitable for online applications. The results from the crill value measurements are presented and discussed based on the data obtained from the crill module of the PulpEye® Analyzer.

Fig 2-5 show the results from crill measurement of mechanical pulp based microfibrils using the PulpEye ${ }^{\circledR}$ CrillEye Instrument. In these figures, the crill values have been plotted against the homogenization time. In Fig 2, the initial crill value was 227 and after $50 \mathrm{~min}$ homogenisation time, the crill value rose to 254 , showing an approximate $11 \%$ increment. When the homogenization time was further increased to $120 \mathrm{~min}$, the crill value was increased by 39 units, indicating an almost $17 \%$ improvement in crill. For TMP based NLC homogenized at $140^{\circ} \mathrm{C}$ (Fig 3), at $50 \mathrm{~min}$, a crill value of 254 was recorded as compared to 227 for the reference samples. The crill value at $120 \mathrm{~min}$ homogenization is 266, which is noted as being almost the same as for samples homogenized at $23^{\circ} \mathrm{C}$ (266).

Fig 4 and 5 show CTMP based NLC homogenized both at $23^{\circ} \mathrm{C}$ and $140^{\circ} \mathrm{C}$ respectively. At $50 \mathrm{~min}$ homogenization time, the crill value was 219 compared to

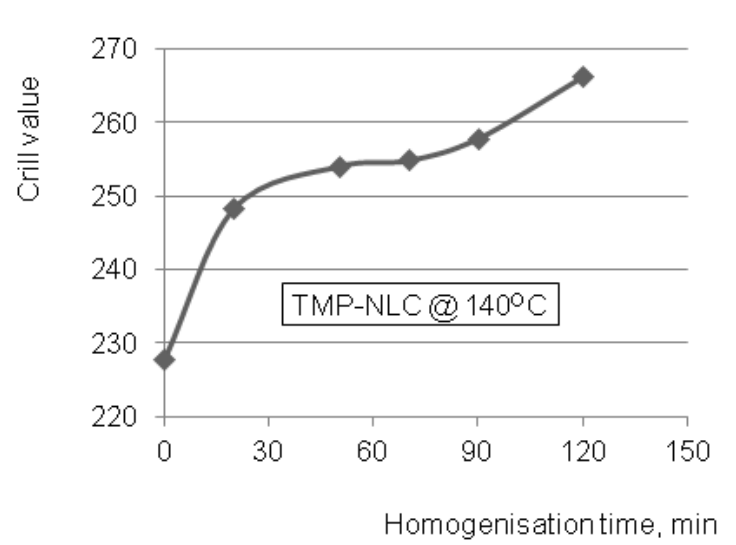

Fig 3 - Crill value of TMP-NLC homogenised after heating to $140^{\circ} \mathrm{C}$ as a function of homogenisation time.

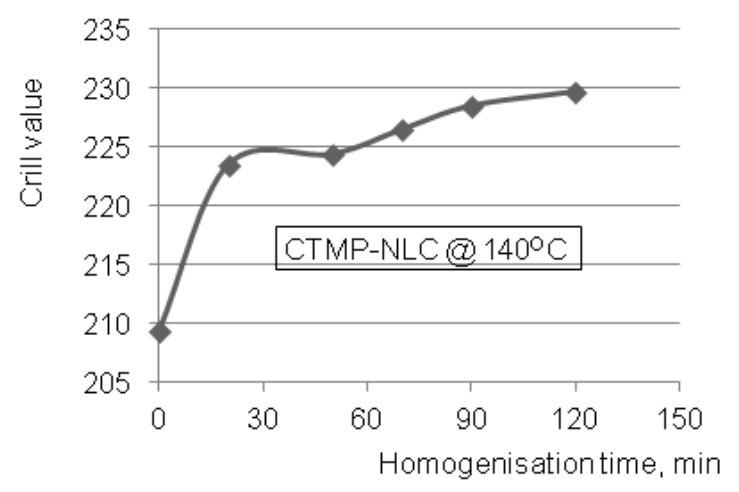

Fig 5 - Crill value of TMP-NLC homogenised after heating to $140^{\circ} \mathrm{C}$ as a function of homogenisation time.

209 for the reference sample, showing an additional 10 unit in the crill value (5\% increment). Further, at $120 \mathrm{~min}$, the crill value was 227, indicating an approximate $9 \%$ increment (Fig 4). As shown in Fig 5, the crill value before homogenization (reference) is 209, and after $50 \mathrm{~min}$, the crill value increased to 224 , showing a $7 \%$ increment in crill value. At $120 \mathrm{~min}$, the crill value was 229 , indicating a $10 \%$ increment.

When increasing the homogenization temperature from 23 to $140{ }^{\circ} \mathrm{C}$, there seems to be no major difference in the crill value for the respective pulp samples (TMP and CTMP). But there is a large difference in crill value between the TMP and the CTMP based nano-lignocellulose. There are at least two possible explanations for the difference in crill value for TMP and CTMP based nano-ligno-cellulose. One is that both pulps have different degree of refining and/or chemical pretreatment during pulp production. Another explanation is due to difference in pulp chemistry; i.e. the introduction of anionically charged groups onto the lignin molecules.

The crill value increases with homogenization time which therefore means that the technique can be used in assessing pulp particles in the sub-micron scale. When comparing the crill value versus homogenization time plots for both TMP-NLC and CTMP-NLC, there appears to be no significant difference in terms of trends. As shown in Figs 2-5, the crill is qualitatively used to assess mechanical pulp based nanocellulose fibrils with respect to homogenization time. The results of crill versus homogenization time were in relative agreement for all 
the samples. There was no significant difference in relation to temperature level treatment in the homogenizer, the crill value showed pretty similar development. It should however be noted that the temperature is rising quite rapidly during homogenisation thereby resulting in the effect that the final temperature when starting at room temperature is in the range of 55 to $65^{\circ} \mathrm{C}$. This could mean that we may have enough softened lignin in the treated material even if we start at room temperature.

\section{Conclusions}

A comparison between the crill value versus the homogenization time of TMP-NLC and CTMP-NLC, homogenized at both $23^{\circ} \mathrm{C}$ and $140^{\circ} \mathrm{C}$, show a relatively close agreement. The CrillEye technique is known to be a fast and robust method for obtaining reliable data. Crill data presented in this work indicates that the fibrillation efficiency is good enough after the first $20 \mathrm{~min}$ of homogenization. More data are however needed for the development of reliable results for mechanical pulp based nano-ligno-cellulose, in order to prove this technique for commercial application.

\section{Acknowledgements}

This study is a part of the Mid Sweden University "FORE" programme. The authors would like to thank European Union and Länsstyrelsen Västernorrland for their financial support. Special thanks to Öjvind Sundvall, PulpEye AB, Örnsköldsvik, Sweden, for inspiring discussions. The authors thank Majid Alimadadi at Mid Sweden University for the schematic diagram of the high pressure homogenizer.

\section{Literature}

Ankerfors, M. (2012): Microfibrillated cellulose: Energy-efficient preparation techniques and key properties. Licentiate Thesis, Department of Fibre and Polymer Technology, Royal Institute of Technology, Stockholm, Sweden.

Charreau, H., Foresti, M.L., Vazquez, A. (2013): Nanocellulose Patents Trends: A Comprehensive Review on Patents on Cellulose Nanocrystals, Microfibrillated and Bacterial Cellulose, Recent Patents on Nanotechnology, 7, 5680.

Eichhorn, S. J., Dufresne, A., Aranguren, M., Marcovich, N. E., Capadona, J. R., Rowan, S. J., Weder, C., Thielemans, W., Roman, M., Renneckar, S., Gindl, W., Veigel, S., Keckes, J., Yano, H., Abe, K., Nogi, M., Nakagaito, A. N., Mangalam, A., Simonsen, J., Benight, A. S., Bismarck, A., Berglund, L. A., Peijs, T. (2010): Review: current international research into cellulose nanofibres and nanocomposites. J. of Materials Science, 45(1), 1-33.

Guay, D., Malandri, N., Schneider, M., Sutherland, N, R., Stephens, A., Rantanen, W., Mattingly, K. (2005): Comparison of Fiber Length Analyzers, in 2005 TAPPI Practical Papermaking Conference Proceedings; CD-ROM, ISBN: 1595100946.

Hansen, P., Sundvall, Ö. (2012): On-line crill sensor commercially available 2012, International Paper Physics and 8th International Paper and Coating Chemistry Conference Stockholm Sweden, June 10-14 2012, poster.
Henriksson, M., Henriksson, G., Berglund, L., Lindström, T. (2007): An environmentally friendly method for enzyme-assisted preparation of microfibrillated cellulose (MFC) nanofibers. European Polym. J., 43(8), 3434-3441.

Herrick, F., Casebier, R., Sandberg, K. (1983): Microfibrillated cellulose: morphology and accessibility. J. Appl. Polym. Sci.: Appl. Polym. Symp 37:797-813 (United States) ITT Rayonier Inc., Shelton, WA.

Hubbe MA, Rojas OJ, Lucia LA, Sain M. (2008): Cellulosic nanocomposites: a review. BioResources; 3: 929-80.

Klemm, D., Kramer, F., Moritz, S., Lindström, T., Ankerfors, M., Gray, D., Dorris, A. (2011): Nanocelluloses: A New Family of Nature-Based Materials. Angewandte Chemie Int. Edition, 50(24), 5438-5466.

Moon RJ, Martini A, Nairn J, Simonsen J, Youngblood J. (2011): Cellulose nanomaterials review: structure, properties and nanocomposites. Chem Soc Rev; 40: 3941-94.

Pääkkö, M., Ankerfors, M., Kosonen, H., Nykänen, A., Ahola, S., Österberg, M., Ruokolainen, J., Laine, J., Larsson, P.T., Ikkala, O. and Lindström, T. (2007): Enzymatic hydrolysis combined with mechanical shearing and highpressure homogenization for nanoscale cellulose fibrils and strong gels. Biomacromolecules, 8(6), 1934-1941.

Pettersson, T. (2010): On-line crill measurements for improved control of refining, Control Systems 2010, SPCI, Stockholm.

Saito, T., Kimura, S., Nishiyama, Y., Isogai, A. (2007): Cellulose nanofibres prepared by TEMPO-mediated oxidation of native cellulose. Biomacromolecules, 8(8), 2485-2491.

Seth, R. (2003): The measurement and significance of fines. Pulp Paper Can., 104(2), 41-44.

Siqueira G., Bras J., Dufresne A. (2010): Cellulosic Bionanocomposites: a review of preparation, properties and applications. Polymers; 2: 728-65.

Siro I. and Plackett D. (2010): Microfibrillated cellulose and new composite materials: a review. Cellulose; 17: 459-94.

Steenberg, B., Sandgren, B., Wahren, D. (1960): Studies on Pulp Crill, Part 1. Suspended fibrils in paper pulp fines, Svensk Papperstidning Nr 12, pp 395-397.

Sundberg, A. and Holmbom, B. (2004): Fines in spruce TMP, BTMP and CTMP - chemical composition and sorption of mannans. Nord. Pulp Paper Res. J., Vol.19 no.2/2004.

Sundholm J. (1999): Papermaking Science and Technology Vol.5; Mechanical Pulping, ISBN 952-5216-05-5, Fapet Oy, P.O. Box 146, FIN-00171 Helsinki, Finland.

Tappi (2011): Roadmap for the development of international standards for nanocellulose, Tappi's International nanotechnology Division

Turbak, A., Snyder, F., Sandberg, K. (1983): Microfibrillated cellulose, a new cellulose product: properties, uses, and commercial potential. J. Appl. Polym. Sci.: Appl. Polym. Symp. 37: 815-827 (United States) ITT Rayonier Inc., Shelton, WA.

Westermark, U. and Capretti, G. (1988): Influence of ray cells on the bleachability and properties of CTMP and kraft pulps. Nord. Pulp Paper Res. J., no.211, 988

Manuscript received September 11, 2013 Accepted November 27, 2013 